\title{
Southport experience with domiciliary ventilation
}

\author{
J D Bingley \\ Clinical Manager, Regional Spinal Injuries Centre, District General Hospital, Town Lane, \\ Southport, Merseyside PR8 6NJ, England.
}

\begin{abstract}
Experience of the Southport Spinal Injuries Centre in reestablishing ventilator dependent patients back in their own homes has confirmed the view that such level of disability need not prevent people from returning to the community and start living again. Convincing the carers in the community and abolishing the traditional boundaries between hospital and community appear to be the fundamental prerequisites. Increased use of advanced assistive technology will enable these disabled people to have more acceptable control of their lives.
\end{abstract}

Keywords: high tetraplegia; ventilator dependence; reestablishment at home.

\section{Introduction}

It has been the experience of spinal injury centres all over the world that more and more people with high tetraplegia are surviving to reach specialised centres, mainly due to improved standards of immediate care at the scene of the accident and informed and positive management in accident departments. It is now widely accepted $^{1.2}$ that ventilator dependence in tetraplegia should not prevent disabled people from returning to their own homes and starting to live again. ${ }^{3}$ The first such patient was admitted to this centre 10 years ago and since then 16 such people have returned home and are now living with a very acceptable level of autonomy and quality of life. The purpose of this paper is to explore the experience of the staff involved at the Southport centre in returning people to their home environment.

\section{The referral pattern}

Though not strictly relevant to this discussion it is important to note that there are patients who do not reach spinal injury centres with expertise in ventilator management. There are at least 4 such people

\footnotetext{
Paper read at the First European Conference on Domiciliary Ventilation and High Spinal Cord Lesion, Southport, England, October 1991.
}

known to our centre; one who died after several weeks in a general hospital, 2 who were in a hospital ward for several years and another still in a general ward after almost 6 months. In Great Britain there is a National Health Service (NHS) and spinal injury centres are at present supraregional services and referral to any centre from any part of the country is feasible as part of the general working system.

\section{Overall findings}

It had been the conviction in Southport that unless the time honoured tradition of hospital centred treatment is radically changed, the care system would continue to be grossly inadequate for the needs of disabled people at large, and inordinately expensive, with substantial pressure for an increase in the number of costly hospital beds and an inevitable increase in staffing requirement. ${ }^{4.5}$ The protocols have been radically changed, need for appointments before a disabled person can come to hospital has been done away with and consultant and senior nurse freely visit homes. Virtually one third of acute work at any given time is being maintained in the community. This has been a fundamental change in culture and working pattern in hospitals. Without this change in culture it is unlikely that the centre would have been able to keep these people with ventilator dependence at home. 
It is indeed ironic that more difficulty has been experienced convincing the medical and nursing professions that keeping ventilator dependent people at home is quite possible without major upheaval, than the patients or their families, who have shown a greater amount of adventure and realism. It is, therefore, very important to convince the professionals that ventilator management is not insurmountable or too technical for most ordinary people. It is important to note that this is not an over-simplification of the entire process. One of the most consistent experiences in Southport is that the relatives of most of our patients have much more expertise than most nurses or doctors unfamiliar with procedures. Familiarity, then, is the operative word rather than a very high level of technical knowledge or professional status.

Community nursing care is an integral part of the NHS in Britain. It has been the experience of the staff in our centre that these nurses cannot really take on a great deal more than that which they undertake as a routine. The conclusion was reached almost 10 years ago that relatives are the only source of continued support and reliability. Relatives will accept quite complicated procedures if they are themselves part of the care pattern that is planned and evolved in hospital and then continued at home. Community nurses and doctors accepting the challenge is a slightly slower process and much of the credit for this must undoubtedly go to the relatives.

Professionals working in healthcare delivery are far behind industry at large in harnessing high technology. ${ }^{6}$ Much is now available to control the environment, embark on learning systems and improve employment prospects using infrared and voice activated systems to control and manage computer based systems, robots and other manipulators. It is also important to realise that no longer is it necessary for a key worker to be in the centre of an expensive city centre. A disabled person, connected to a ventilation system can design machinery or buildings, manipulate the stock market, direct the finance using voice operated computers and data transfer systems and still remain in his home. It is a fundamental aim of the centre to convince and convert industrialists, not just doctors and nurses.

One of the most important variables which must be addressed is cost. Healthcare providers must calculate whether systems can afford domiciliary ventilation. However, the real question which must be asked is: What are the alternatives? It costs about $£ 200$ a day to keep a patient in hospital in the UK. The nursing, physiotherapy and other services, and expensive antibiotics to fight the eternal danger due to cross infection in a hospital all make hospital a very expensive place. Capital expense is the same whether the patient is at home or not, as the equipment is no longer available for general use in hospital. About $£ 25,000$ is required as capital cost to buy equipment, together with approximately $£ 4000$ per annum for disposables and $£ 2500$ ( $10 \%$ capital costs) for equipment maintenance. The real cost of keeping a ventilator dependent person at home is about $£ 6000$, or $£ 7000$ if account is taken of the additional nursing or physiotherapy. This is in marked contrast to $£ 73,000$ a year if the patient remains in a hospital. On a financial basis alone, it is not appropriate to keep such individuals in hospital. Even if a further $£ 25,000-30,000$ is spent installing a modern computer based environment system, considerable savings are still made.

The fundamental step, therefore, is comprehensive negotiation between professionals, social services, industrialists and doctors, but above all with the patient and the relatives. What is really needed is an enlightened, honest, adventurous yet realistic team prepared to see disability as a family matter rather than as an interesting exercise in nursing, physiotherapy or any other conventional discipline. Relatives would agree with professionals if they receive proof that caring for their disabled relative is something that is undertaken together and that the traditional barrier between hospital and community should be abolished. Disabled people belong to their homes. It is the duty of those involved in spinal care to keep them there and to provide for their needs there and not in the sterile atmosphere of a hospital. Such a realisation is at the very centre of the entire process. The team and 
the relative must have a very close relationship from the start and this relationship must be fostered and developed into a trusting mutual bond. Information is the basis of such trust and there are three essentiai working rules: (1) communications must always be truthful; (2) information should not frighten; and (3) there must remain some hope. In establishing such a relationship the patients' relatives realise and accept that there is substantial danger to their life and that the decision to send them home is a deliberate and adventurous one. as the alternatives are most unsatisfactory or dismal. Always a source of amazement is the competence and enthusiasm shown by apparently ordinary people in learning all about the mechanics of ventilation, basic rules of sterility, technical procedures such as changing of tracheostomy tubes, essential physiotherapy for chest care and above all when to-and more important, when not to-raise the alarm.

Relatives need rest and they need it fully knowing that care is not compromised. Centres should therefore not only educate them to become experts in looking after the disabled person but also provide care for the carers. Respite admissions should not be something they have to apologetically ask for but something that is offered as a matter of course. Without such support it is unfair, unhelpful and in the long run unacceptable to try and send a ventilator patient home.

\section{Conclusion}

There is need for detailed and comprehensive planning by a dedicated multidisciplinary team for reinstallation of ventilator dependent patients in their own homes. It is essential that the health authorities are convinced that such an exercise is justifiable not only on humanitarian but on economic grounds. It has been shown that such profoundly disabled people can be cared for in their own homes safely and with quality of life.

\section{References}

1 Gardner BP, Theocleous F. Watt JWH and Krishnan KR (1985) Ventilation or dignified death for patients with high tetraplegia. $B r$ Med J 291: 1620-1622.

2 Bingley JD (1990) Rehabilitation after spinal cord injury. Nursing Standard 4(38): 27-30.

3 Whitneck GG, Carter RE, Charlifue SW. Hall K.M. Menter RR. Wilkerson MA. Wilmott CB (1985) A collaborative study in high quadriplegia. Rocky Mountain Regional SI System. Craig Hospital. Englewood Colorado.

+ Bingley JD (1991) Domiciliary ventilation: a new direction in community care for high tetraplegia. Critical Care Forum. Royal College of Nursing. Newcastle.

5 Purtillo RB (1986) Ethical issues in treatment of chronic ventilator dependent patients. Arch Phys Med Rehabil 67: 718-721.

6 Fraser MH, Krishnan KR (1991) Introducing 'high tech' assistive equipment at an early stage in the tetraplegic rehabilitation programme. J Am Para Soi 14: 91. 